\title{
Reflexiones sobre la época Flavia en Brigantium a partir de los datos proporcionados por la Terra Sigillata
}

\author{
$M^{a}$. Catalina López Pérez
}

\section{Resumen}

Los resultados obtenidos a partir de la terra sigillata han permitido analizar la evolución urbana de la antigua Brigantium. La práctica ausencia de las producciones itálicas y gálicas junto a la presencia de materiales hispánicos fechados en época flavia, llevan a fijar en esta etapa, el momento en que da comienzo el desarrollo del enclave.

PALABRAS CLAVE: terra sigillata, navegación atlántica, comercio romano, evolución urbana, A Coruña, Galicia.

\section{Summary}

the results obtained from terra sigillata have enabled to analyze the urban evolution of the ancient Brigantium. The practically absence of Italian and Gallic production together with the presence of Hispanic material dated in flavia time lead to set the moment when the enclave did begin to develop in this stage.

KEY WORDS: terra sigillata, Atlantic sailing, Roman commerce, urban evolution, A Coruña, Galicia.

Desde que en 1985 la arqueología urbana dio sus primeros pasos, han sido numerosas las aportaciones que se han venido realizando sobre el conocimiento del yacimiento romano de Brigantium. Disponemos por tanto de un corpus bibliográfico amplio, que en buena parte resulta deudor de la contribución realizada por esta arqueología de urgencia. De igual modo que en otros yacimientos urbanos, los resultados de estas intervenciones han permitido un avance en el conocimiento de la Coruña romana, difícilmente alcanzable de otro modo.

Sin embargo las propias limitaciones que presentan este tipo de excavaciones, no han conseguido dar solución a una serie de cuestiones que todavía resultan problemáticas. Entre ellas se encuentran aspectos tales como la promoción jurídica a la categoría de municipio, el topónimo del propio enclave, o la concreción de su etapa inicial. El presente trabajo no pretende, ni mucho menos, dejar zanjados estos temas sino simplemente aportar datos que permitan acercarse a alguno de ellos desde una nueva perspectiva. De modo concreto podemos señalar como nuestro principal objetivo el de utilizar la información obtenida a partir de un material muy concreto, la terra sigillata, para incidir principalmente sobre lo referido a las fechas iniciales de este núcleo.

Aceptamos las objeciones que se nos pudieran realizar acerca del hecho de que únicamente esta- 
mos tomando en consideración una parte del registro arqueológico. No obstante hemos de indicar que por el momento son limitadas las publicaciones en las que se dan a conocer otros grupos de materiales, u otro tipo de referencias cronológicas que pudieran contrastar las proporcionadas por la sigillata (Bello Diéguez, 1995; Naveiro López, 1981; 1982; 1991a).

No obstante, y con respecto a ello, hemos de señalar que la sigillata presenta características que la hacen adecuada a este propósito. El hecho de constituir un buen referente cronológico, así como el identificarse con un material que a la altura del fin del s. I d.C. ya ha sustituido su carácter de lujo por el de un bien de uso doméstico y cotidiano, va a convertirlo en un buen indicador de las fluctuaciones que experimenta el desarrollo urbano. Es por ello que consideramos que los resultados extraídos de estas vajillas pueden aportar datos a tener en cuenta en el conocimiento del enclave brigantino y principalmente de la etapa citada.

\section{CUESTIONES PREVIAS}

Antes de centrarnos en el material de estudio, debemos primeramente analizar de forma somera, tanto las propias características del enclave, como ciertas opiniones que han sido planteadas acerca del mismo. No se trata de proporcionar un vaciado exhaustivo de la información que se dispone hasta el momento, sino simplemente de acercar- nos al estado actual en que se halla la investigación en una serie de cuestiones, sobre las que como veremos, no siempre ha habido acuerdo.

Una idea tradicionalmente repetida en la bibliografía apunta a que la posición privilegiada que Brigantium detenta en las costas gallegas, la convierte en un punto de referencia obligado en la navegación atlántica (Fig. 1). Situado en la península que por el oeste limita la ría de A Coruña, ofrece unas buenas condiciones para el recalado de barcos al encontrarse protegido de corrientes y vientos. Estas características geográficas han sido destacadas como determinantes en el desarrollo de este vicus, puesto que en esta zona del litoral galaico, la navegación se desarrolla ante las circunstancias adversas que impone una costa abrupta y recortada.

A esta directa vinculación con las rutas atlánticas ha de añadirse la integración a la red viaria terrestre a partir de su condición de mansio de la vía XX. Así aparece citada en las fuentes clásicas, y es éste un hecho a tener en cuenta puesto que dicha condición la conecta de forma directa con Lugo, la capital del conventus lucensis. Todo ello ha llevado a plantear su identificación tanto con un puerto de escala en la navegación de altura (Naveiro López, 1991a: 154), como con el establecimiento que sucederá a la vecina Iria Flavia en las labores portuarias de abastecimiento de Lugo (Carreño Gascón, Rodríguez Colmenero, 1991: 27).
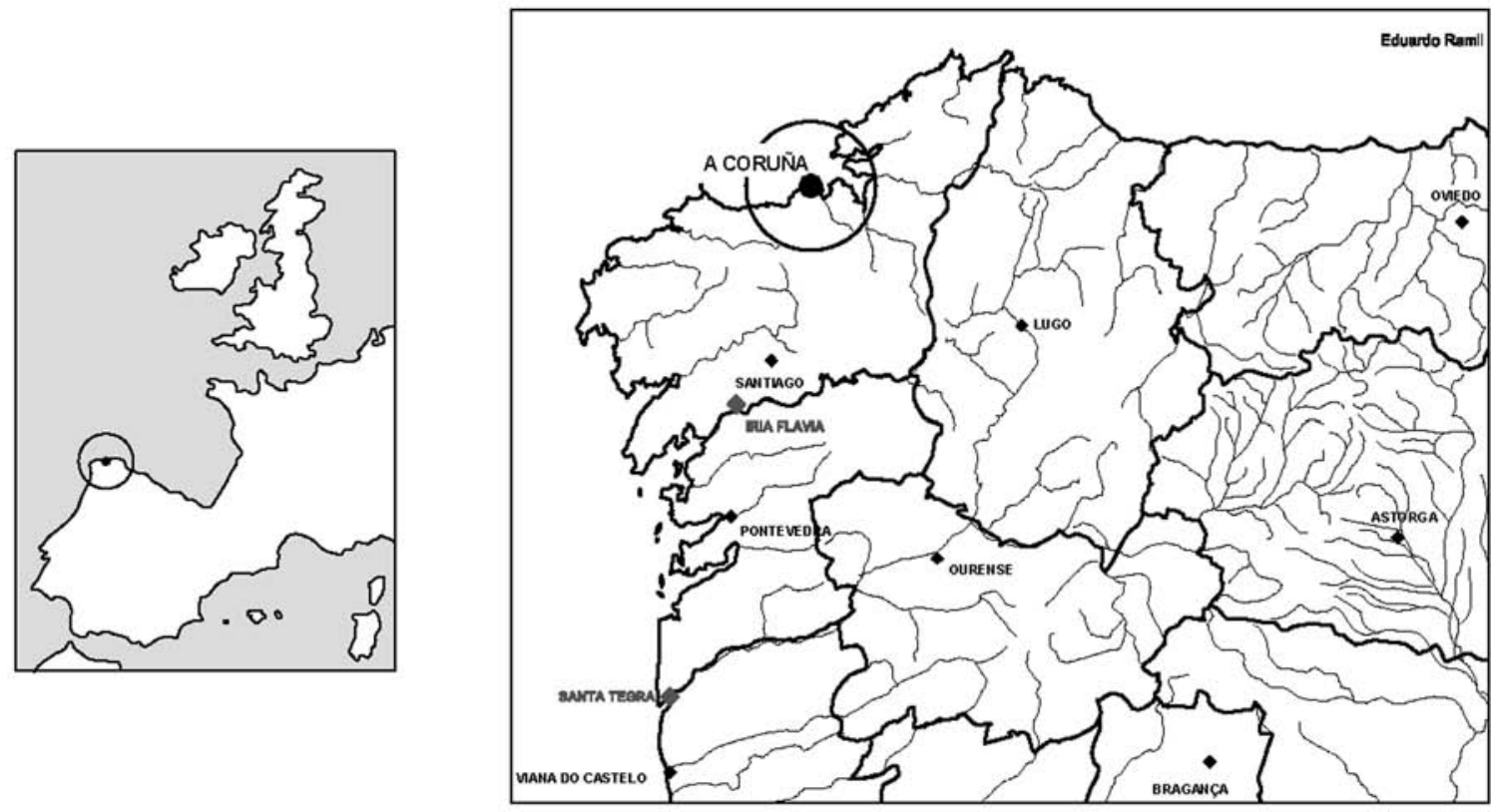

Figura 1. Localización de Brigantium en la fachada atlántica y en el Noroeste. 
El yacimiento se localiza en el promontorio rocoso en el que se asienta la actualmente conocida como Ciudad Vieja, y se extiende por la lengua arenosa sobre la que se encuentra el barrio de la Pescadería (Fig. 2). Es en el extremo sudoeste de la citada Ciudad Vieja donde han sido localizados los restos más antiguos, proporcionando cronologías que nos llevan a momentos anteriores al cambio de era. Paralelamente ha podido observarse que su volumen aumenta hacia el final del s. I d. C., hecho que por otra parte ha de ser puesto en relación con el desarrollo que experimentan las rutas atlánticas tras las conquistas de Augusto y Claudio en el Norte de Europa y Britannia
(Naveiro López, 1991a: 131; Morillo Cerdán, 2003: 22).

Si nos centramos en la evolución que ha experimentado el enclave, comenzaremos por encontrar cierta divergencia de opiniones acerca de la cronología que se refiere a sus orígenes. Consideramos que respecto a este aspecto, debe llamarse la atención sobre el hecho de que tanto el volumen de estos materiales como el de otras evidencias contemporáneas, resulta muy limitado, y ello ha llevado a que sea difícil concretar una fecha de comienzo. De este modo encontramos autores que de forma laxa sitúan esos momentos en torno al s. I d. C. (Pérez Losada, 2002: 117),

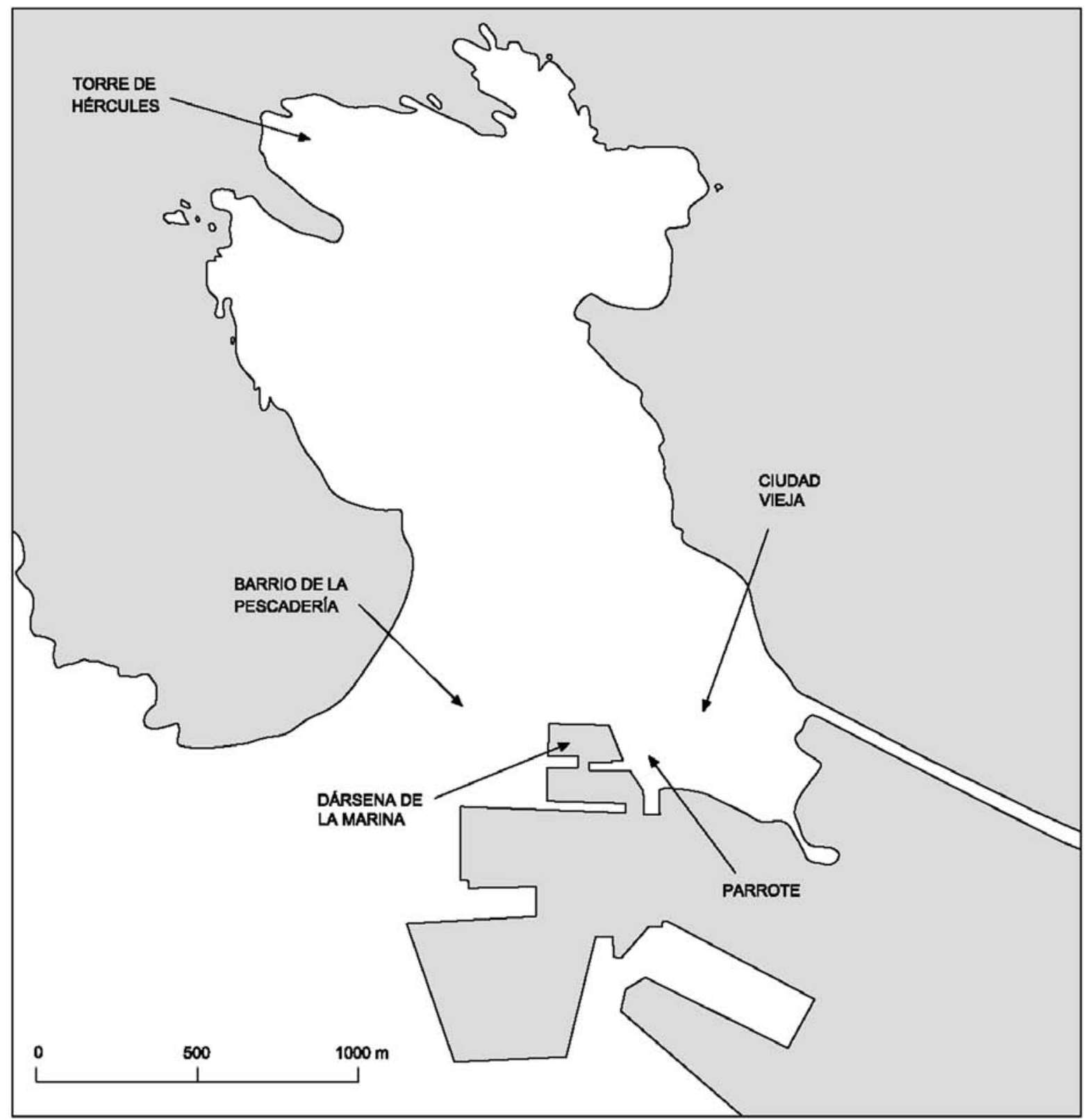

Figura 2. Península en la que se asienta el yacimiento. 
los que identifican a Brigantium con una posible creación imperial del s. II (San Claudio Santa Cruz, 2003: 121), así como las que se limitan a señalar estos siglos I y II como la etapa de mayor desarrollo del enclave (Bello Diéguez, 1995: 88; Naveiro López, 1991b: 17; Naveiro López, Pérez Losada, 1992: 66; Vázquez Gómez, 1991: 39).

Frente a estas propuestas encontramos las de aquellos que, tomando en consideración la toponimia, identifican a Flavium Brigantium como una creación flavia (Tranoy, 1992: 79; 1993: 34), o como un establecimiento que en ese momento experimenta un proceso de "refundación o renovación" con el que inicia su despegue (González García, 2003: 111, 259). Como se verá en el posterior desarrollo de este trabajo, son estas últimas propuestas las que consideramos que han sido contrastadas positivamente por los resultados obtenidos a partir de la sigillata.

El consenso lo encontramos a la hora de señalar al s. II como la etapa de mayor expansión del enclave, y el Bajoimperio como la de decadencia y retracción del poblamiento que en estos momentos quedará reducido a la zona del Parrote (Bello Diéguez, 1995: 91; Naveiro López, 1994: 55; López Pérez, 2008: 401).

Igualmente encontramos posturas bastante concordantes en el tema referido a la identificación de Brigantium con una statio del portorium. Entre los primeros en formular esta hipótesis encontramos a Balil Illana (1977: 128), Le Roux (1977: 97) y Tranoy (1981a: 187; 1981b: 113), para quienes la documentación epigráfica localizada en A Coruña ponía en evidencia la presencia de exsactores, funcionarios imperiales dedicados al cobro de impuestos que en este caso posiblemente se relacionen con la recaudación del portorium, el que gravaba la circulación de mercancías. La hipótesis sobre la posible existencia en A Coruña de una statio aduanera, fue apoyada por diversos autores (Barreiro Fernández, 1986: 52; Vázquez Gómez, 1991: 39; Naveiro López, 1994: 58; Naveiro López, Pérez Losada, 1992: 68), y ello a pesar de que el trabajo de Pereira Menaut revisó estos epígrafes rechazando la lectura de exsactor proponiendo la de ex actor (CIRG I, 4; $C I R G$ I, 5), con lo que se pasaba a estar ante un funcionario cuya actividad no se concretaba.

Intervenciones recientes realizadas en la calle Real de A Coruña, han incidido positivamente sobre esta cuestión, puesto que en ellas ha sido puesto al descubierto un epígrafe funerario sobre cuya leyenda, esta vez sí, parece existir acuerdo en señalar como dedicante a un exsactor (Tomás Botella, e. p.; Rodríguez Colmenero, 2005: 883)

Posturas poco concordantes suscita igualmente la hipótesis acerca de la posible promoción al estatus jurídico de municipio del núcleo brigantino en época de Vespasiano. A este planteamiento se llega a partir de la inclusión del término Flavium en el topónimo. Con respecto a ello, Tranoy, a pesar de identificar el enclave con una creación de época flavia tal y como se ha indicado, en su momento no lo incluyó dentro del listado que elabora sobre los municipios flavios (Tranoy, 1981a: 205; 1993: 34), hecho que sí van a apoyar otros autores (Morillo Cerdán, 1999: 351; Naveiro López, Pérez Losada, 1992: 66).

Respecto del topónimo, hay que hacer mención a la hipótesis planteada por Bello Diéguez (1995: 62) en la cual se pone en duda la veracidad del mismo. Según este autor, Flavium Brigantium, podría corresponder únicamente a un error, una confusión con el topónimo que propone como original: Pharum Brigantium. Es ésta una hipótesis que cuenta con cierta aceptación (Pérez Losada, 2002: 119; San Claudio Santa Cruz, 2003: 121), pero que en cualquier caso, se presenta de difícil contrastación en el estado actual de la investigación. Por otra parte, esta propuesta del topónimo Pharum Brigantium, es en la que se basa el propio Bello Diéguez (1995: 61), para "dejar en suspenso" el hipotético ascenso del enclave a la categoría de municipio flavio.

A lo anterior debe sumarse el que se haya llamado la atención sobre una serie de contradicciones que no contribuyen a aclarar el estatus que pudo haber detentado Brigantium. Éstas se concretan en la existencia de una colección epigráfica de marcado carácter romano, clásico, que no concuerda por otro lado con la ausencia de estructuras de carácter monumental, una ausencia que ha sido puesta en evidencia de forma reiterada a partir de las numerosas intervenciones de urgencia realizadas hasta el momento.

\section{RESULTADOS A PARTIR DEL MATE- RIAL DE ESTUDIO}

Hechas estas consideraciones previas, pasamos a centrarnos en el objeto de este trabajo, es decir, sobre cómo los resultados obtenidos a par- 
tir del estudio de las diferentes producciones de sigillata, han realizado aportaciones a la delimitación de los momentos iniciales del yacimiento. Es éste un planteamiento que ya hemos defendido previamente y sobre el que ahora volvemos con la intención de concretar ciertos aspectos (López Pérez, 2008).

Ya hemos visto que desde el punto de vista de la arqueología se ha tendido a proporcionar una fecha poco precisa entre los siglos I y II. Como se ha indicado, los restos más antiguos han sido recogidos en puntos concretos de la Ciudad Vieja y su volumen corresponde fundamentalmente a algunos fragmentos aislados de cerámica campaniense y ánforas Dressel 1.

Su presencia es desde luego indicativa de la existencia de una ocupación en torno al cambio de era o en momentos quizá anteriores. Sin embargo, este reducido número de evidencias lleva a preguntarse sobre el tipo de entidad poblacional al que pudieron haber correspondido. A partir de lo que hoy se conoce, parece que estamos ante un núcleo de reducidas dimensiones, posiblemente vinculado de forma directa con una actividad portuaria de características no suficientemente conocidas por ahora.

El porcentaje casi anecdótico que se registra entre las sigillatas itálicas y gálicas, así como las cronologías que estas piezas apuntan, indican que ese escaso peso poblacional del enclave debió de haberse mantenido al menos durante la etapa previa a los flavios (Fig. 3). Concretamente su volumen se reduce en el caso de la vajilla itálica a un total de 2 fragmentos, en tanto que en el de la producción gálica no va más allá de 10 piezasi Respecto a las primeras citadas hay que destacar que los distintos autores que han incidido sobre el tema (Caamaño Gesto, 1983: 229; Carreño Gascón 1997: 256; César Vila, 2009: 132; César Vila, López Pérez, 2008: 242; López Pérez, 2004: 513; Morais, 2005: 148; Naveiro López, 1991a: 29), coinciden en que para el Noroeste el período de comercialización de la TSI corresponde al primer tercio del s. I d.C., aceptando no obstante el

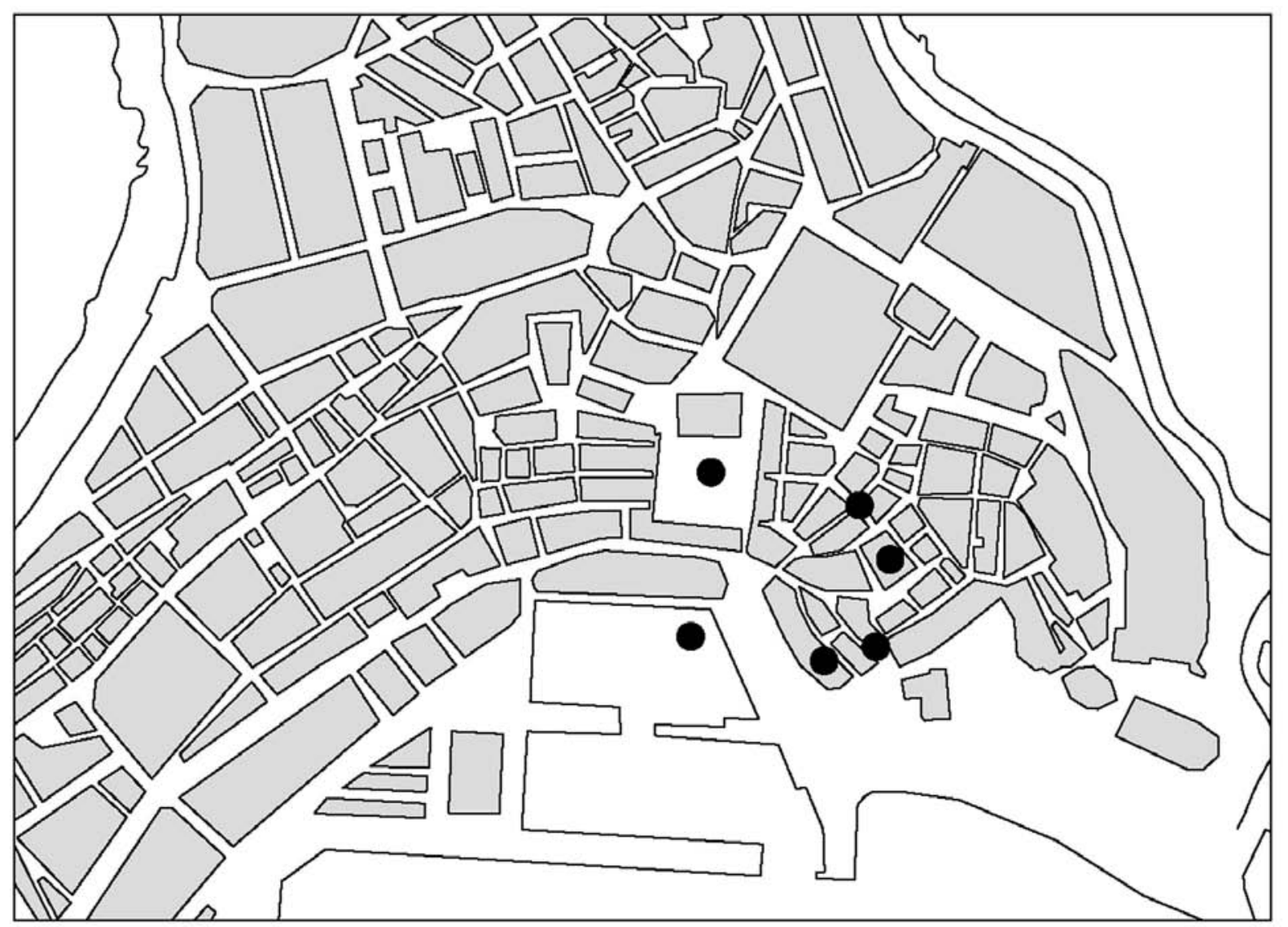

0

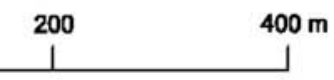

Figura 3. Localización de hallazgos previos a la etapa Flavia. 
hallazgo de ejemplares aislados fechados en momentos anteriores y posteriores al tramo cronológico citado. Este tipo de piezas anormalmente tempranas o de cronología avanzada las encontramos igualmente entre las sigillatas gálicas, para las que sin embargo se acepta un período de importación preferente que se desarrolla entre la década de los años 40 d.C. y la etapa flavia (Caamaño Gesto, 1983: 233; Carreño Gascón, 1997; Fernández Ochoa, Zarzalejos Prieto, García-Entero, García Marcos, Menéndez Granda, Sánchez Hidalgo, Foucher, 2005: 86; López Pérez, 2004: 99; 2005: 69; Morais, 2005: 180; Naveiro López, 1991: 31). Estos últimos momentos parecen encontrarse determinados con fiabilidad en Galicia, dado que hasta el momento no ha sido localizado ningún ejemplar identificado con los llamados servicios flavios (Vernhet, 1976).

Esta limitada llegada de material preflavio consideramos que constituye una contradicción en un enclave habitacional de clara vocación atlántica como reiteradamente se le ha venido calificando, y mayormente si se compara con otros yacimientos galaicos como Santa Tegra o la vecina Iria Flavia, donde en una pequeña excavación de una superficie aproximada de tan solo 300 $\mathrm{m}^{2}$ han sido recogidos un conjunto que ronda los 200 fragmentos de sigillata gálica. Esta contradicción se hace extensible por otra parte a la costa cantábrica, puesto que son numerosos los yacimientos que ofrecen unas nutridas colecciones de sigillatas. Solo por citar algunas aludiremos a los conjuntos recogidos en el área asturiana (Sánchez Hidalgo, Menéndez Granda, 2005; Zarzalejos Prieto, 2005), Flaviobriga (Ruíz Gutiérrez, 19971998), Santoña (Fernández Ochoa, Morillo Cerdán, 2003: 148), o Irún (Urteaga Artigas, Amundaray Gangoiti, 2003; Rodríguez Salís, Luc Tobie, 1971).

La presencia de sigillata en estos yacimientos muestra la existencia de un flujo comercial en las costas atlánticas, del que sin embargo no parece participar Brigantium, o al menos lo que corresponde al yacimiento localizado en tierra. Con esto último queremos hacer una llamada de cautela, puesto que los materiales que hasta el momento se conocen como procedentes de los fondos de la Dársena, evidencian la llegada de importaciones en momentos tempranos, de las que sin embargo existe escasa constancia en tierra (Naveiro López, 1981: 123; 1982: 66).
A la vista de lo expuesto, se plantea una nueva pregunta, ¿podemos tomar esta descompensación de restos, los localizados en tierra y los procedentes del fondo de la Dársena, como indicativos de que Brigantium fue enclave portuario antes que vicus?. Los datos de los que se dispone hasta el momento, parecen apuntar en esa dirección, aunque posiblemente sea el estudio sistemático del puerto el que pueda llegar a despejar esta cuestión.

$\mathrm{Si}$ aceptamos el que esta serie de restos antiguos solo están indicando una ocupación de tipo residual, entonces, ¿cuándo podemos empezar a hablar de Brigantium como un núcleo de cierta entidad poblacional?. La respuesta a esta pregunta es la que como ya indicamos, centra el objetivo de este trabajo, y para ello hemos de volver nuevamente sobre los porcentajes de sigillata, las formas registradas y sus implicaciones cronológicas.

Los bajos porcentajes registrados entre las producciones itálicas y gálicas ofrecen un fuerte contraste con lo constatado para la T.S.H. Esta última, al igual que sucede en la mayor parte de la provincia de A Coruña o de la ciudad de Lugo, constituye la vajilla fina mejor representada, llegando a suponer en Brigantium un volumen que ronda el $80 \%$ respecto del total de la sigillata localizada. Estos elevados porcentajes se relacionan no sólo con la expansión que los talleres riojanos experimentan a partir de finales del s. I d.C., sino que necesariamente habrán de responder de igual modo al desarrollo urbano de nuestro enclave. La cuestión ahora se centra en determinar el momento en que estas piezas comienzan a llegar a Brigantium.

El estado actual de la investigación acepta que la llegada al Noroeste de las primeras sigillatas hispánicas tiene lugar en épocas muy tempranas para la producción riojana. Así se deduce del hallazgo de ejemplares identificados con las producciones precoces localizadas en Lugo (Carreño Gascón, 1997: 258), o los ejemplos de piezas identificadas con formas y decoraciones propias de las etapas iniciales de los talleres de Tricio. Sin embargo, nada de esto ha sido localizado en Brigantium. Los ejemplares más antiguos parecen adscribirse por el contrario a la etapa flavia. Para sostener esta premisa nos hemos fijado en aquellas formas y decoraciones que pueden proporcionar una mayor precisión cronológica para esta etapa; nos referimos concretamente a los ejemplares de Forma 29 y a la decoración de metopas. 
Según la revisión realizada a la tipología y cronología de la producción hispánica por Roca Roumens y Fernández García (1999: 287), a la citada forma 29 le corresponde una pervivencia que oscila entre las décadas de los años 40/50 y 80 , mientras que de modo generalizado tiende a apuntarse a la mencionada época flavia como el momento de floruit de la decoración metopada.

Entre las colecciones brigantinas, este tipo de piezas no cuenta con porcentajes elevados pero si con una presencia que cuando menos puede considerarse significativa; la serie de individuos identificados con la Forma 29 supone un total de 50, conjunto al que deben sumarse 22 fragmentos indeterminados decorados con motivos metopados (Fig. 4). Como decimos nos hemos fijado en un grupo de materiales cuya cronología proporciona fechas muy concretas respecto de la etapa analizada, pero es de suponer que la forma citada no constituyó la única importada, sino que llegaría acompañada de otras de cronología menos precisa para este momento.
La relación que se establece entre la presencia anecdótica de la sigillata gálica y el número significativo de piezas hispánicas de Forma 29 y con decoración metopada, apunta que el establecimiento de una importación regular de sigillata, comienza a partir de época flavia. La idea hacia la que conduce este progresivo aumento de materiales, tiende por tanto a identificar estos momentos flavios como una etapa de cambio en Brigantium, un punto de inflexión a partir del cual tiene lugar un crecimiento urbano que no culminará hasta el s. II, cuando el enclave adquiera sus mayores dimensiones.

Se responde así a la cuestión planteada acerca de los orígenes del yacimiento brigantino, puesto que consideramos que la sigillata ha contrastado positivamente las hipótesis formuladas por Tranoy y González García sobre el carácter flavio del yacimiento.

Si aceptamos esta cronología, debemos entonces replantearnos una serie de cuestiones, ahora bajo esta nueva perspectiva. De este modo habría

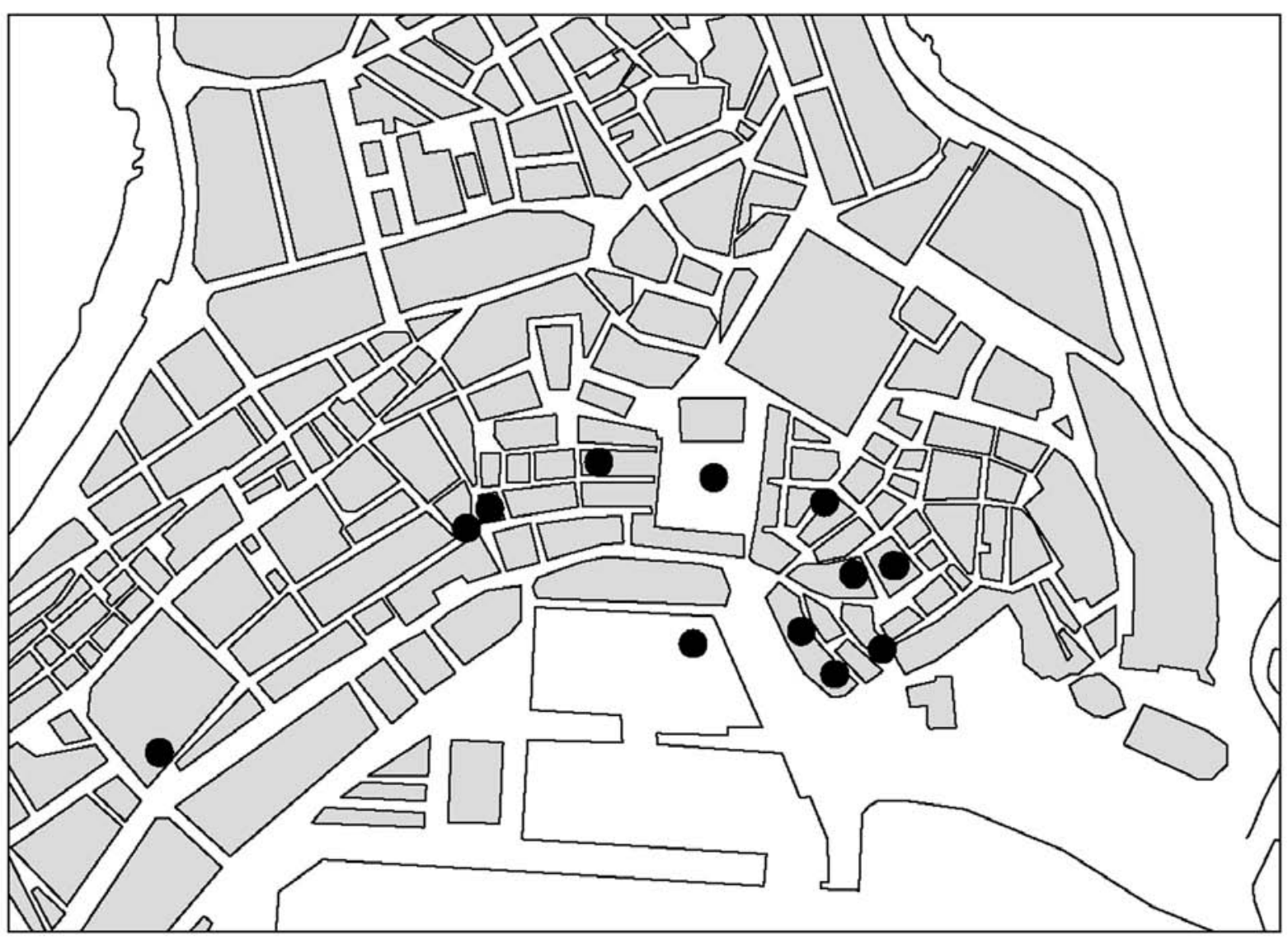

0 200 $400 \mathrm{~m}$

Figura 4. Localización de hallazgos fechados entre época flavia y el cambio de siglo. 
nuevamente que retomar la cuestión relativa al topónimo, puesto que si efectivamente estamos ante un núcleo cuyo primer desarrollo comienza con la dinastía flavia, hay que considerar cuando menos la posibilidad de que esta cronología pueda suponer el rechazo del componente Pharum del topónimo en favor del de Flavium Brigantium. Según Tranoy (1981a: 199; 1993: 33) el interés de la citada dinastía por acelerar la integración del Noroeste en el Imperio, les lleva a incrementar la red urbana incentivando la creación de nuevos núcleos, que independientemente de su situación jurídica, pasarán a llevar nombres flavios. Entre estos establecimientos nombra a la citada Flavium Brigantium. Con estos comentarios no pretendemos dejar zanjada la cuestión relativa al topónimo, sino simplemente apuntar una reflexión que necesariamente habrá de ser tomada en consideración en estudios posteriores.

Por otra parte cabría preguntarse igualmente acerca de las razones que explican la expansión del enclave en estos momentos flavios. Para buscar la respuesta a esta pregunta, podemos centrarnos primeramente en el edificio más emblemático de la ciudad romana, la torre de Hércules, dado que las cronologías de su construcción parecen estar en relación a las del desarrollo brigantino.

A pesar de que la construcción de esta estructura fue vinculada desde el s. XVIII a la época del emperador Trajano, en un trabajo reciente se adelanta su construcción a la segunda mitad del s. I, proponiendo la época de Vespasiano como la opción "más coherente con la arqueología" (Bello Diéguez, 2009: 64). Estas cronologías flavias son precisamente hacia las que apunta la colección de sigillatas procedente de las excavaciones del edificio (López Pérez, 2004: 66) ${ }^{\mathrm{ii}}$, puesto que en ella se observa la misma relación entre la ausencia de piezas gálicas y la presencia de Formas 29 hispánicas. De confirmarse la hipótesis sobre la construcción del edificio en época de Vespasiano, estaríamos ante una concordancia entre la cronología de construcción de la torre y las que proponemos para el desarrollo del núcleo habitacional (López Pérez, 2008: 402).

Continuando con las causas que explican estas cronologías flavias de Brigantium, debe llamarse la atención acerca del hecho de que no estamos ante un caso aislado. El crecimiento y desarrollo urbano que nuestro núcleo experimenta en época flavia, se encuentra igualmente registrado en dis- tintos puntos del Cantábrico, entre los que se cuentan los establecimientos portuarios de Gijón (Fernández Ochoa, 1999: 1115; Fernández Ochoa, García Díaz, Gil Sendino, 2003: 105), Castro Urdiales (Iglesias Gil, 2003: 157; Iglesias Gil, Ruíz Gutiérrez, 2002: 19) e Irún (Urteaga Artigas, 2003: 196).

Estos yacimientos al igual que A Coruña, han sido calificados por la bibliografía como centros de redistribución y consumo, gracias por una parte, a su directa relación con las rutas atlánticas a partir de la privilegiada posición que detentan, como por su conexión con la red viaria terrestre. Estamos por tanto ante unos yacimientos que comparten una cronología y funcionalidad común, unos paralelismos que no han dejado de llamar la atención a ciertos investigadores (Fernández Ochoa, Morillo Cerdán, 1994: 229).

En relación a ello debe destacarse que esta expansión urbana resulta coincidente en el tiempo con la ya citada reordenación administrativa y promoción urbana llevada a cabo por los flavios. Por otra parte y aún teniendo en cuenta los condicionantes propios de cada establecimiento, se ha tendido a ver como factor determinante del impulso de estos núcleos, el desarrollo y consolidación que las rutas comerciales atlánticas experimentan tras la política de conquistas llevadas a cabo por el Imperio; concretamente se señalan como decisivas la victoria de Augusto sobre los cántabros, la conquista de Britania por Claudio y la configuración del limes germánico. De este modo se llegaría a la consolidación de una ruta atlántica cuyo trazado permitiría la conexión de la zona del Estrecho con el canal de la Mancha a través del Cantábrico. A pesar de que se ha destacado que el principal objetivo de la citada ruta estaría en relación al abastecimiento del ejército, se considera que paralelamente este tráfico implicaría igualmente un comercio civil (Fernández Ochoa, Morillo Cerdán, 2009: 122; Morillo Cerdán, 2003: 24). En esta ruta comercial, Brigantium se configuraría como un punto de paso obligado como así parece avalar la presencia del faro, la citada Torre de Hércules. Tanto la existencia del faro como quizá el origen y desarrollo de la propia Brigantium, se han puesto en relación con este avituallamiento militar (Bello Diéguez, 2009: 63).

No obstante y como ya señalamos, el carácter que detentó el núcleo coruñés sigue presentando algunos puntos oscuros. Queda todavía por valo- 
rar el papel desempeñado por el enclave portuario de Vigo en estos circuitos comerciales atlánticos y la relación que éste mantendría respecto a Brigantium. La bibliografía publicada, aunque limitada, presenta unos resultados un tanto sorprendentes, puesto que nos hablan de una zona de gran vitalidad comercial que recibe un gran volumen de materiales, entre los que se cuentan un elevado número de sigillatas tardías de procedencia dispar (Fernández Fernández, 2007), así como un importante conjunto de ánforas Haltern 70 que en el castro de Vigo suma un total de 951 individuos (Morais, Carreras Monfort, 2004: 103).

\section{CONSIDERACIONES FINALES}

Ya finalmente y para terminar queremos recordar que nuestra única pretensión ha sido la de acercarnos a una serie de problemas, partiendo para ello, de la información proporcionada por un grupo de material muy concreto: la terra sigillata. Recordemos que las características del propio material, es decir, el constituir un bien de uso doméstico y fiel reflejo por tanto de este ámbito, han permitido analizar y contrastar hipótesis que han sido planteadas acerca diversos aspectos del yacimiento romano de A Coruña.

Como se ha comprobado todavía existen aspectos poco conocidos y controvertidos sobre esta etapa. Es por ello que consideramos que los resultados y reflexiones expuestas han de formar parte de un trabajo conjunto, puesto que en un futuro habrán de ser necesariamente relacionadas con otros grupos de materiales o evidencias. A pesar de ello, consideramos haber dado respuesta al objetivo central de este trabajo al haber contrastado positivamente aquellas propuestas que establecían en torno a época flavia el despegue habitacional de Brigantium.

\section{BIBLIOGRAFÍA}

BALIL ILLANA, A. (1977): "Reflejos galaicos de la familia Caesaris" Actas del Coloquio Internacional sobre el Bimilenario de Lugo, 123129, Lugo.

BARREIRO FERNÁNDEZ, J. R. (1986): Historia de la ciudad de La Coruña, A Coruña.

BELlO DIÉGUEZ, J. M. (1995): Historia de La Coruña, A Coruña.

BELLO DIÉGUEZ, J. M. (2009): “Brigantium y su faro. Contextos arqueológicos en la ciudad de $\mathrm{A}$
Coruña" ARIAS VILAS, F., FERNÁNDEZ OCHOA, C., MORILlO, A., (eds.): Torre de Hércules: finis terrae lux. Simposio sobre os faros romanos e a navegación occidental na antiguidade. Brigantium, 20, 43-66, A Coruña.

CAAMAÑO GESTO, J. M. (1983): “Cerámicas finas de importación en la época romana en Galicia" Estudos de cultura castrexa e de historia antiga de Galicia, 225-246, Santiago de Compostela.

CARREÑO GASCÓN, Ma . C. (1997): “Cerámica fina de mesa: la terra sigillata en Galicia" Galicia castrexa e romana, 255-260, Santiago de Compostela.

CARREÑO GASCÓN, Mª C., RODRÍGUEZ COLMENERO, A. (1991): “Tras la huella del Lugo romano" Ciudad y torre. Roma y la ilustración en La Coruña, 23-27, A Coruña.

CÉSAR VILA, M. (2009): A terra sigillata do xacemento romano de Bueu e o seu contexto no marco pontevedrés. Memoria de Licenciatura. Universidad de Santiago de Compostela.

CÉSAR VILA, M., LÓPEZ PÉREZ, Mª C. (2008): "Aportaciones al conocimiento del comercio de sigillata en la fachada atlántica del Noroeste peninsular" Actes du Congrès de l'EscalaEmpúries, 1er-4 mai 2008: les productions céramiques en Hispanie tarraconaise (IIe siècle avant J.-C. - VIe siècle après J.-C.). Actualité des recherches céramiques, 241-254, Marsella.

FERNÁNDEZ FERNÁNDEZ, A., LAGO CERVIÑO, M., (2007): "Cerámicas finas tardorromanas orixinarias de África e de Medio Oriente atopadas na intervención da rúa Rosalía de Castro 1992 (Vigo)" Castrelos, 13, 26-51, Vigo.

FERNÁNDEZ OCHOA, C., (1999): "La ciudad romana de Gijón: orígenes y dinámica histórica" Rodríguez Colmenero, A. (coord.): Los Orígenes de la ciudad en el noroeste hispánico, , Lugo.

FERNÁNDEZ OCHOA, C., MORILLO CERDÁN, A., (1994): "La ruta marítima del cantábrico en época romana" Zephyrus, 46, 225-232

FERNÁNDEZ OCHOA, C., MORILLO CERDÁN, A., (2003): "El puerto de Santander y otros enclaves marítimos de la Cantabria romana" FERNÁNDEZ OCHOA, C., (ed.): Gijón, puerto romano. Navegación y comercio en el Cantábrico durante la antigüedad, 134-151, Gijón.

FERNÁNDEZ OCHOA, C., ZARZALEJOS PRIETO, M., GARCÍA-ENTERO, V., GARCÍA MARCOS, V., MENÉNDEZ GRANDA, A., SÁNCHEZ HIDALGO, E., FOUCHER, V., (2005): "La difusión de los talleres de La Graufesenque y Montans en el cuadrante norocci- 
dental de Hispania: materiales para un corpus de marcas de alfarero" NIETO, X., ROCA ROUMENS, M., VERNHET, A., SCIAU, P., (eds), Monografías 6, Museu d'Arqueologia de Catalunya, 79-102, Barcelona.

FERNÁNDEZ OCHOA, C., MORILLO CERDÁN, A., (2009): ARIAS VILAS, F., FERNÁNDEZ OCHOA, C., MORILlO, A., (eds.): "Faros y navegación en el Cantábrico y Atlántico norte" Torre de Hércules: finis terrae lux. Simposio sobre os faros romanos e a navegación occidental na antigüidade. Brigantium, 20, 43-66, A Coruña

GONZÁLEZ GARCÍA, F. J. (2003): Os Ártabros: estudio xeográfico e etnohistórico, Ourense.

IGLESIAS GIL, J.M. (2003): "Flaviobriga" FERNÁNDEZ OCHOA, C., (ed.): Gijón, puerto romano. Navegación y comercio en el Cantábrico durante la antigüedad, 153-161, Gijón.

IGLESIAS GIL, J.M., RUÍZ GUTIÉRREZ, A. (2002): "Castro Urdiales romano: de puerto a ciudad" Fortea Pérez, J.I. (ed.) Transiciones: Castro Urdiales y las cuatro villas de la costa de la mar en la historia, 19-38, Santander.

LE ROUX, P. (1977): “Lucus Augusti, capitale administrative au Haut-Empire" Actas del Coloquio Internacional sobre el Bimilenario de Lugo, 83101, Lugo.

LÓPEZ PÉREZ, Mª C. (2004): El comercio de terra sigillata en la provincia de A Coruña, Brigantium, 6, A Coruña.

LÓPEZ PÉREZ, Ma . C. (2005): “Galicia y los contactos comerciales con el sur de la Galia: la Terra Sigillata Sudgálica" NIETO, X., ROCA ROUMENS, M., VERNHET, A., SCIAU, P., (eds), La difusió de la Terra Sigillata Sudgàl.lica al nord d'Hispania, Monografías 6, Museu d'Arqueologia de Catalunya, 63-78, Barcelona.

LÓPEZ PÉREZ, Ma. C. (2008): “Brigantium como centro de consumo de terra sigillata" 1 Congreso Internacional de Arqueoloxía de Vilalba, Fervedes, 5, 397-403.

MORAIS, R., CARRERAS MONFORT, C., (2004): "Geografía del consum" CARRERAS MONFORT, C., AQUILUÉ, X., (eds.) Culip VIII i les amfores Haltern 70, Monografías 5, Museu d'Arqueologia de Catalunya, Centre d’Arqueologia Subaquàtica, 93-116, Girona.

MORAIS, R., (2005): Autarcia e comercio em Bracara Augusta, Braga

MORILLO CERDÁN, A. (1999): “Asentamientos militares y civiles en el origen del fenómeno urbano en el noroeste peninsular” RODRÍGUEZ COLMENERO, A., (coord.), Los orígenes de la ciudad en el noroeste hispánico: actas del Congreso Internacional, Lugo 15-18 de mayo de 1996, 339-354, Lugo.

MORILLO CERDÁN, A. (2003): "la navegación oceánica durante la época romana: de la imagen legendaria a la vertebración de un espacio marítimo atlántico" FERNÁNDEZ OCHOA, C., (ED.): Gijón, puerto romano: navegación y comercio en el cantábrico durante la antigüedad, 17-41, Barcelona.

NAVEIRO LÓPEZ , J. L. (1981): “As ánforas romanas de A Coruña (I)" Brigantium, 2, 117-126, A Coruña.

NAVEIRO LÓPEZ, J. L. (1982): “As ánforas romanas de A Coruña (II)” Brigantium, 3, 63-74, A Coruña.

NAVEIRO LÓPEZ, J. L. (1991a): El comercio antiguo en el N.W. peninsular, Monografías urxentes do museu, 5, A Coruña.

NAVEIRO LÓPEZ, J. L. (1991b): “Comercio atlántico en Galicia en época romana" Ciudad y torre. Roma y la ilustración en La Coruña, 15-17, A Coruña.

NAVEIRO LÓPEZ, J. L. (1994): El golfo Ártabro. Arqueología e historia del gran puerto de los Galaicos Lucenses, A Coruña.

NAVEIRO LÓPEZ, J. L., PÉREZ LOSADA, F. (1992): "Un finisterre atlántico en época romana: la costa galaica (NW de la Península Ibérica)" Current research on the romanization of the western provinces. BAR, 63-90, Oxford.

CIRG, I, PEREIRA MENAUT, G. (1991): Corpus de Inscripciones Romanas de Galicia I. Provincia de A Coruña, Santiago de Compostela.

PÉREZ LOSADA, F. (2002): Entre a cidade e a aldea: estudio arqueohistórico dos "aglomerados secundarios" romanos de Galicia, Brigantium, 13, A Coruña.

ROCA ROUMENS, M., FERNÁNDEZ GARCÍA, Ma . I. (eds.) (1999): Terra sigillata hispánica. Centros de fabricación y producciones altoimperiales, Jaén.

RODRÍGUEZ COLMENERO, A. (2005): "Las nuevas stationes lucensis et brigantina en el finisterre ibérico del Imperio Romano" Paleohispánica, 5, 873-892.

RODRÍGUEZ SALÍS, J., LUC TOBIE, J., (1971): "Terra sigillata de Irún" Munibe, 2-3, 187-221, San Sebastián. 
RUÍZ GUTIÉRREZ, A., (1997-1998): “Flaviobriga, puerto comercial entre Hispania y la Galia: estudio del comercio de terra sigillata a través de un lote de Castro Urdiales (Cantabria)" Aquitania, XV, 147-166

SAN CLAUDIO SANTA CRUZ, M. (2003): "El puerto de Brigantium y la navegación romana en el Atlántico norte" FERNÁNDEZ OCHOA, C. (ed.), Gijón, puerto romano: navegación y comercio en el Cantábrico durante la Antigüedad, 121-133, Barcelona.

SÁNCHEZ HIDALGO, E., MENÉNDEZ GRANDA, A. (2005): "Avance al estudio de la Terra sigillata sudgálica del castro de Chao Samartín (Grandas de Salime, Asturias)" FERNÁNDEZ OCHOA, C., GARCÍA DIAZ, P. (eds.), III Congreso Internacional de Arqueología en Gijón. Unidad y diversidad en el Arco Atlántico en época romana, 251-258, Gijón.

TOMÁS BOTELLA, V., "Intervención arqueológica no no 34 da rúa Real de A Coruña (2000 - 2004)" Brigantium, en prensa.

TRANOY, A. (1981a): La Galice romaine. Rechercher sur le nord-ouest de la Péninsule ibérique dans l'Antiquité, París.

TRANOY, A. (1981b): "Romanisation et monde indigene dans la Galice antique: problèmes et perspectives" Primera Reunión Gallega de Estudios Clásicos, 105-121, Santiago de Compostela.

TRANOY, A. (1992): "Permanences indigènes et romanisation en Galice" Actas do I Congreso Internacional da Cultura Galega, 77-80, Santiago de Compostela.

TRANOY, A. (1993): “Communautés indigènes et promotion juridique dans le nord-ouest ibérique" Ciudad y comunidad cívica en Hispania. Siglos II y III d.C., Collection de la Casa Velázquez, 40, 27-35, Madrid.

UNZUETA PORTILLA, M., (1996): “El período romano en la vertiente cantábrica de la Comunidad Autónoma vasca: las evidencias arqueológicas del proceso romanizador (siglos I a. C. a II d. C.)" FERNÁNDEZ OCHOA, C. (coord.): Los finisterres atlánticos en la antigüedad : época prerromana y romana, 165-170, Madrid.

URTEAGA ARTIGAS, M.M. (2003): "El puerto romano de Oiasso (Irún) y la desembocadura del río Bidasoa" FERNÁNDEZ OCHOA, C. (ed.), Gijón, puerto romano: navegación y comercio en el Cantábrico durante la Antigüedad, 193-211, Barcelona.
URTEAGA ARTIGAS, M.M., AMUNDARAY GANGOITI, L., (2003): "Estudio de la cerámica procedente del puerto romano de Irun: avance de las investigaciones" Arkeolan, 11, 59-104, Irún.

VÁZQUEZ GÓMEZ, X. (1991): "La Coruña en época romana" Ciudad y torre. Roma y la ilustración en La Coruña, 35-40, A Coruña.

VERNHET, A. (1976): "Création flavienne de six services de vaisselle á la Graufesenque" Figlina, 1, $13-27$

ZARZALEJOS PRIETO, M., (2005): "Comercio y distribución de cerámicas en Asturias" FERNÁNDEZ OCHOA, C., GARCÍA DIAZ, P. (eds.), III Congreso Internacional de Arqueología en Gijón. Unidad y diversidad en el Arco Atlántico en época romana, 163-189, Gijón.

i Aprovechamos esta oportunidad para corregir el error cometido en una publicación anterior (López Pérez, 2008: 402), donde se señalaba que el volumen de TSG localizada en A Coruña ascendía a 3 fragmentos, número que en realidad corresponde hasta el momento a los 10 aquí referenciados.

ii En relación a la cronología inicial que en su momento propusimos para las sigillatas procedentes de la torre de Hércules (López Pérez, 2004: 67), queremos llamar la atención sobre la errónea interpretación que se ha realizado sobre la misma en una publicación reciente (Bello Diéguez, 2009: 60). En nuestro trabajo planteábamos como fechas iniciales, el final del s. I o los principios del s. II, para una colección que como indicamos, no registraba ningún ejemplar de sigillata gálica, y cuyas piezas más tempranas correspondían a fragmentos metopados y de Forma 29 hispánica. En base a la cronología absoluta comúnmente aceptada para la citada Forma 29, este autor rechaza las fechas propuestas por nosotros para la mencionada colección y apunta a un momento indeterminado de la segunda mitad del s. I al tener en cuenta dos fragmentos de Lucerna de forma Loeschcke IV así como una serie de fragmentos indeterminados de paredes finas (Bello Diéguez, 2009: 64).

Queremos indicar que no compartimos esta apreciación puesto que más significativo que la presencia de las Formas 29, las paredes finas y las citadas lucernas, es sin embargo, la ausencia de las sigillatas gálicas, una tendencia que como estamos viendo, se reproduce en el resto del enclave. En un yacimiento que de forma reiterada ha sido identificado como un puerto integrado en las rutas atlánticas, la falta de estos materiales 
indica una cronología posterior a su momento de comercialización, es decir, la etapa flavia.

No obstante consideramos necesario matizar nuestra anterior propuesta rechazando la ampliación de las cronologías iniciales hasta los principios del s. II. Con respecto a ello debemos indicar que en el momento de realización de nuestro trabajo, la información publicada sobre los resulta- dos de las excavaciones era muy limitada, y no incluía otros estudios de materiales que contrastasen las cronologías dadas por la sigillata, así como tampoco ponía en duda la datación trajanea de la torre. Proponer como segunda hipótesis los principios del s. II, a pesar de lo bien conocidas que para nosotros resultan las cronologías de la Forma 29 hispánica, simplemente nos pareció una llamada a la prudencia. 